\title{
Does the type of a centre in which the resection of extensive tumours of the limbs and truck is performed, affect the patients'survival?
}

Dear Editor,

Modern reconstructive surgery is based on the appropriate application of the available reconstruction methods, including microvascular ones. Their combination with radio- and chemotherapy leads to optimal treatment results. Nevertheless, the issue of immediate resections and reconstructions in the treatment of extensive tumours still arises many unnecessary controversies.

Although the origin of the concept of immediate reconstruction after resection goes back to the $18^{\text {th }}$ century [1], the theses contained in Halsted's works from the end of the 19th century [2] with fundamental significance for oncological surgery, led to a situation in which the closure of postresection bed and let alone the use of more advanced techniques of the defect completion, materialised as late as in the 1990s [3]. The results of the studies from this period proved that immediate reconstruction - even in the case of extensive resections - is literally safe. Moreover, planning of appropriate reconstructive surgical procedure allows for a maximally extensive resection, which additionally increases the radicality of the surgery $[4,5]$.

Oncological and Reconstructive Surgery Clinic of the Maria Sklodowska-Curie National Research Institute of Oncology, Gliwice Branch has a rich clinical material concerning immediate reconstructions in the case of extensive tumour resections of almost any region of the body. Each year, more than 200 microsurgical procedures are performed in the clinic.

The treatment results of the above group of patients with extensive tumours of the trunk and the limbs were analysed (fig. 1). The obtained results support the thesis of the effectiveness of the microsurgery techniques in the restoration of the limbs function and also make a valuable point in the debate concerning the extensive resections outside the centres which have appropriate experience and the equipment base for such procedures.

Recently some tendency to perform extensive tumour resections in the centres which do not have large experience in such procedures has been observed. There is a concern that - with regards to the lack of possibility of performing an immediate reconstruction - the scope of the resection may not be adequate in terms of obtaining complete radicality of the procedure.

Oncological and Reconstructive Surgery Clinic of the Maria Sklodowska-Curie National Research Institute of Oncology, Gliwice Branch analysed the treatment results of 71 patients operated in 2006-2017 for extensive tumours of the trunk and limbs. The basic clinical data of the study group are presented in tables I and II.

The obtained results show, among others, that the patients with primary treatment (resection surgery) outside the National Research Institute of Oncology had a significantly shorter recurrence free survival. The patients whose resection surgeries were performed in the National Research Institute of Oncology had a longer recurrence-free survival periods than the patients treated in other centres $(p<0.05)$. The comparison showed that the statistically significant difference in a five-year recurrence-free survival period is present when the primary surgery is performed in the National Research Institute of Oncology (fig. 2).

The above results may be regarded as an important voice justifying performing extensive resective and reconstructi-

\section{How to cite:}

Drozdowski PH, Krakowczyk ŁJ, Maciejewski AJ. Does the type of a centre in which the resection of extensive tumours of the limbs and truck is performed, affect the patients' survival? NOWOTWORY J Oncol 2020; 70: 158-160. 

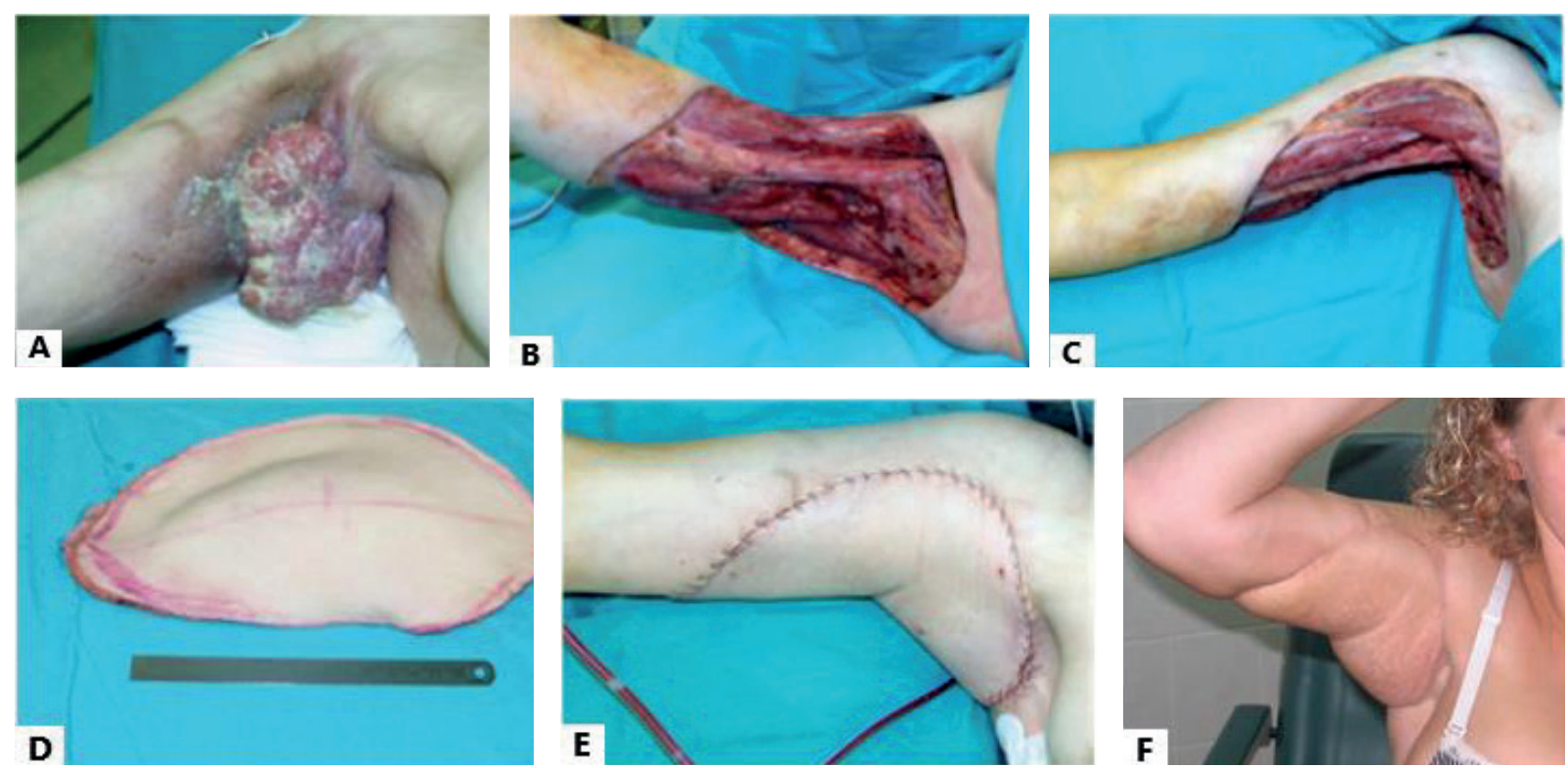

Figure 1. A - an extensive tumour of the right shoulder and axilla; $B, C$ - post-resection bed sparing axillary vessels and the nerves of the brachial plexus; $\mathrm{D}$ - dissected antero-lateral flap of the thigh; $\mathrm{E}$ - the flap on the donor site anastomosed to the subscapular vessels; $\mathrm{F}$ - remote post-operative results

Table I. Age characteristics of selected patients

\begin{tabular}{|c|c|c|c|c|}
\hline \multirow[t]{2}{*}{ Variable } & Total & Female subjects & Male subjects & Fvs. M \\
\hline & $n=71$ & $n=27$ & $n=32$ & $p$ \\
\hline \multicolumn{5}{|c|}{ Age (year of life): } \\
\hline $\mathrm{M} \pm \mathrm{SD}$ & $56.1 \pm 15.5$ & $59.7 \pm 15.0$ & $53.8 \pm 15.5$ & \multirow{3}{*}{0.121} \\
\hline $\mathrm{Me}\left[\mathrm{Q}_{1} ; \mathrm{Q}_{3}\right]$ & $58[46,65]$ & $62[48,72]$ & $55[46,63]$ & \\
\hline Min-Max & $19-86$ & 29-82 & 19-86 & \\
\hline
\end{tabular}

Table II. Clinical characteristics of the primary tumour and its treatment in the patient study group

\begin{tabular}{|c|c|c|c|c|c|c|c|}
\hline \multirow[t]{3}{*}{ Variable } & \multicolumn{2}{|c|}{ Total } & \multicolumn{2}{|c|}{ Female subjects } & \multicolumn{2}{|c|}{ Male subjects } & \multirow{2}{*}{$\frac{\text { Fvs. M }}{\mathrm{p}}$} \\
\hline & \multicolumn{2}{|c|}{$\mathrm{n}=71$} & \multicolumn{2}{|c|}{$n=27$} & \multicolumn{2}{|c|}{$n=44$} & \\
\hline & $\mathrm{n}$ & $\%$ & n & $\%$ & $\mathrm{n}$ & $\%$ & 0.045 \\
\hline \multicolumn{8}{|c|}{ Location of the primary tumour: } \\
\hline Hand and arm & 9 & $12.7 \%$ & 4 & $14.8 \%$ & 5 & $11.4 \%$ & \multirow{6}{*}{0.045} \\
\hline Shoulder and shoulder girdle & 10 & $14.1 \%$ & 2 & $7.4 \%$ & 8 & $18.2 \%$ & \\
\hline Foot, lower thigh & 17 & $23.9 \%$ & 3 & $11.1 \%$ & 14 & $31.8 \%$ & \\
\hline Thighs, groins, buttocks & 22 & $31.0 \%$ & 14 & $51.9 \%$ & 8 & $18.2 \%$ & \\
\hline Front chest & 11 & $15.5 \%$ & 3 & $11.1 \%$ & 8 & $18.2 \%$ & \\
\hline Back chest & 2 & $2.8 \%$ & 1 & $3.7 \%$ & 1 & $2.3 \%$ & \\
\hline \multicolumn{7}{|c|}{ Histopathological assessment of the primary tumour: } & \multirow{7}{*}{0.316} \\
\hline Ca plano & 24 & $33.8 \%$ & 9 & $33.3 \%$ & 15 & $34.1 \%$ & \\
\hline Sarcomas & 26 & $36.6 \%$ & 10 & $37.0 \%$ & 16 & $36.4 \%$ & \\
\hline Melanomas & 6 & $8.5 \%$ & 2 & $7.4 \%$ & 4 & $9.1 \%$ & \\
\hline $\mathrm{BCC}$ & 5 & $7.0 \%$ & 1 & $3.7 \%$ & 4 & $9.1 \%$ & \\
\hline Other & 7 & $9.9 \%$ & 5 & $18.5 \%$ & 2 & $4.5 \%$ & \\
\hline Non oncological & 3 & $4.2 \%$ & 0 & $0.0 \%$ & 3 & $6.8 \%$ & \\
\hline \multicolumn{7}{|c|}{ TNM assessment of the primary tumour } & \multirow{2}{*}{0.022} \\
\hline $1-\mathrm{T} 1$ and $\mathrm{T} 2$ & 50 & $70.4 \%$ & 25 & $92.6 \%$ & 25 & $56.8 \%$ & \\
\hline
\end{tabular}




\begin{tabular}{|c|c|c|c|c|c|c|c|}
\hline $2-\mathrm{T} 3$ and $\mathrm{T} 4$ & 7 & $9.9 \%$ & 0 & $0.0 \%$ & 7 & $15.9 \%$ & \\
\hline $3-\mathrm{N}+$ with $\mathrm{T} 1$ and $\mathrm{T} 2$ & 8 & $11.3 \%$ & 1 & $3.7 \%$ & 7 & $15.9 \%$ & \\
\hline $4-\mathrm{N}+$ with $\mathrm{T} 3$ and $\mathrm{T} 4$ & 3 & $4.2 \%$ & 1 & $3.7 \%$ & 2 & $4.5 \%$ & \\
\hline 5 - does not apply & 3 & $4.2 \%$ & 0 & $0.0 \%$ & 3 & $6.8 \%$ & \\
\hline \multicolumn{7}{|l|}{ Centre where the surgery was performed: } & \multirow{4}{*}{0.457} \\
\hline At the $\mathrm{Ol}$ & 49 & $69.0 \%$ & 21 & $77.8 \%$ & 28 & $63.6 \%$ & \\
\hline Outside Ol & 11 & $15.5 \%$ & 3 & $11.1 \%$ & 8 & $18.2 \%$ & \\
\hline Resection outside Ol, reconstruction at the $\mathrm{OI}$ & 11 & $15.5 \%$ & 3 & $11.1 \%$ & 8 & $18.2 \%$ & \\
\hline
\end{tabular}

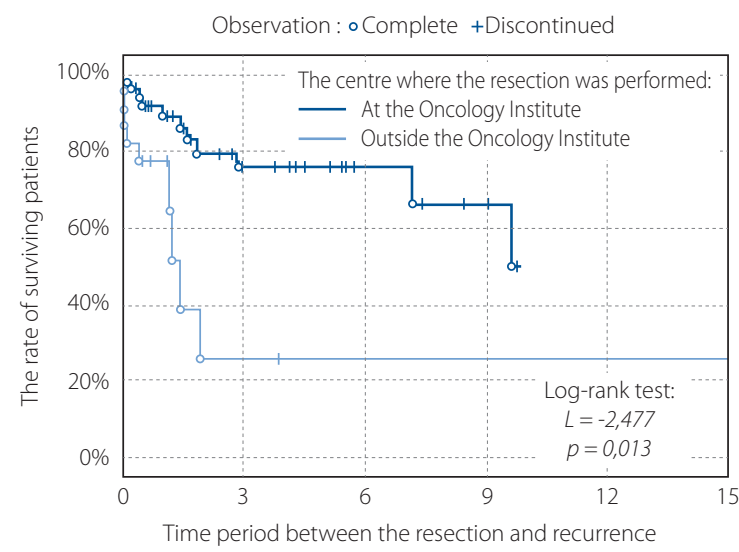

Figure 2. Kaplan-Meier curves of the recurrence free survival after the resection in patients with regards to the difference in the centre in which the procedure was performed

ve surgeries on advanced tumours in the centres with large experience in this respect. This is important especially in the times when some resection procedures, for economic reasons are transferred to the centres which do not have appropriate base for a compre- hensive treatment and thus are unable to guarantee the best possible treatment results to their patients. Piotr H. Drozdowski, Łukasz J. Krakowczyk, Adam J. Maciejewski Oncological and Reconstructive Surgery Clinic, The Maria Sklodowska-Curie National Research Institute of Oncology, Gliwice Branch, Poland e-mail:piotr_drozdowski@wp.pl

\section{References}

1. Tagliacozzi G. De Curtorum Chirurgia per insitionem. Bindoni, Venecja 1597.

2. Halsted WS. I. The Results of Radical Operations for the Cure of Carcinoma of the Breast. Ann Surg. 1907; 46(1): 1-19, doi: 10.1097/00000658190707000-00001, indexed in Pubmed: 17861990.

3. Ho AL, Lyonel Carre A, Patel KM. Oncologic reconstruction: General principles and techniques. J Surg Oncol. 2016; 113(8): 852-864, doi: 10.1002/jso.24206, indexed in Pubmed: 26939879.

4. Parrett BM, Kashani-Sabet M, Leong SPL, et al. The safety of and indications for immediate reconstruction of head and neck melanoma defects: our early experience. Ann Plast Surg. 2014; 72 Suppl 1: S35-S37, doi: 10.1097/SAP.0000000000000166, indexed in Pubmed: 24691340.

5. Gieni M, Avram R, Dickson L, et al. Local breast cancer recurrence after mastectomy and immediate breast reconstruction for invasive cancer: a meta-analysis. Breast. 2012; 21(3): 230-236, doi: 10.1016/j. breast.2011.12.013, indexed in Pubmed: 22225710. 